\section{THE EFFECT OF CASTING TEMPERATURE ON THE FATIGUE PROPERTIES OF CAST NICKEL ALUMINIDE ALLOYS}

\author{
Brian Gieseke and Vinod K. Sikka \\ Metals \& Cercmics Division \\ Oak Ridge National Laboratory \\ P.O. Box 2008 \\ Oak Ridge, TN 37831
}

lap $-9 / 0938--3$
CONF-910938--3

DE92 000432

\section{Abstract}

The results of high cycle fatigue tests at $650^{\circ} \mathrm{C}$ on several cast $\mathrm{Ni}_{3} \mathrm{Al}$ alloys are reported and compared to cast IN-713C. These alloys include IC-221M and several variations to the IC-221M composition. The effect of casting temperature is investigated using castings poured at three different temperatures spanning a $56^{\circ} \mathrm{C}$ range. The results show that IC-221M cast at the highest temperature has the best fatigue strength, exceeding that for IN-713C. In these alloys, crack initiation occurs at shrinkage microporosity and the effect of casting temperature on porosity is related to the observed differences in fatigue lives.
\end{abstract}

\title{
Introduction
}

Nickel aluminides have been the subject of considerable study following the discovery that small additions of boron overcome the problems of low ductility in polycrystalline $\mathrm{Ni}_{3} \mathrm{Al}$ materials $[1,2]$. Several promising alloys have been developed [3], including; IC-50, IC-218LZr, IC-218, IC-221, IC-357, and IC-396M. In these alloy designations, IC stands for intermetallic compound. The chemical compositions of each can be found in reference [4]. Each alloy has a composition tailored to enhance a specific property. For example, IC-218LZr, IC-218, and IC-221 contain chromium in addition to aluminum for improved ductility in the temperature range of 600 to $800^{\circ} \mathrm{C}$. IC-396M is MASTER

Research sponsored by the U.S. Department of Energy, Assistant Secretary for Conservation and Renewable Energy, Office of Industriai Technologits, Advanced Industrial Concepts Division, Advanced Industrial Concepts Materials Program, under contract DE-AC05-840R21400 with Martin Marietta Energy Systems, Inc. 
a high-strength castable alloy containing $3 \%$ molybendum in addition to chromium and aluminum and was designed as a candidate material for uses such as turbine components in truck engines.

Early fatigue data showed that alloy IC-396M displayed lower fatigue resistance in comparison to IC-221. However, IC-221 suffered from low room-temperature strength, and as a result, a new alloy designated IC-221M was developed to be a high-strength, castable alloy with improved high cycle fatigue resistance. The problem of low room-temperature strength was overcome in IC-221M by the addition of $1.43 \%$ molybendum. While the fatigue resistance of this material is better than that for IC-396M, considerable variation in fatigue lives still remains. Hence, a better understanding of the fatigue behavior is needed along with an understanding of the effect of casting variables on fatigue properties. This paper examines the effect of casting temperature on the fatigue properties of as-cast IC-221M at $650^{\circ} \mathrm{C}$.

\section{Procedure}

Several cast $\mathrm{Ni}_{3} \mathrm{Al}$ alloys were tested, including IC-221M and slight modifications of IC-221M where the ratio of Mo to $\mathrm{Zr}$ has been varied. Chemical compositions for IC-221, IC-221M and two variations of IC-221M are listed in Table 1. The compositions of two additional batches of IC-221M specimens are shown to show the possible variation in the chemistry. The tensile properties of the IC-221M alloys are given in Table 2 for a temperature of $650^{\circ} \mathrm{C}$.

These alloys were investment cast under vacuum into near-net sized specimen blanks having diameters of $6.75 \mathrm{~mm}$. Initially, all specimen blanks were all cast at the same nominal temperature, $\mathrm{NT}^{\circ} \mathrm{C}$. Once an optimum alloy composition was selected (i.e., IC-221M), subsequent crstings of IC$221 \mathrm{M}$ were cast at temperatures $28^{\circ} \mathrm{C}$ above and below this nominal temperature.

Specimens were produced from the blanks by threading the ends and machining a polished, 
hourglass gage section with a nominal diameter of $5.08 \mathrm{~mm}$. Fatigue tests were conducted in laboratory air at $650 \pm 2^{\circ} \mathrm{C}$ using a servohydraulic test system and induction heating. Temperatures were monitored at each end of the gage length and in the center. The center thermocouple was held in contact with the specimen and covered with insulation. The majority of tests were conducted at one of three stress levels, including; 517, 586, and $621 \mathrm{MPa}(75,85,90 \mathrm{ksi})$. These correspond roughly to 75,85 , and $90 \%$ of the $0.2 \%$ yield stress. In all the tests, a haversine loading waveform was employed at a frequency of 20 Hertz, using a load ratio (R) of 0.05 . These loading conditions were chosen to match those previously used to generate fatigue data on cast IC-396M and IN-713C.

\section{$\underline{\text { Results }}$}

The results of the fatigue tests are shown in Fig. 1 along with limited results generated on ascast specimens of $\mathrm{IN}-713 \mathrm{C}$ in our laboratory. The $\mathrm{IN}-713 \mathrm{C}$ specimens were cast and tested under identical conditions as the nickel aluminides. IN-713C is one material that $\mathrm{Ni}_{3} \mathrm{Al}$ alloys may replace, hence data for it are included in the figure for reference. Considerable scatter is readily noted in the nickel aluminide data. At $517 \mathrm{MPa}$, the scatter covers two orders of magnitude in life. At $586 \mathrm{MPa}$, the scatter is even greater, with lives ranging over three orders $c$ : magnitude. The spread in the nickel aluminide data extends to both sides of the line representing the fatigue behavior of IN-713C. (Insufficient data exists to determine the scatter in the IN-713C data.) In general, specimens cast $28^{\circ}$ above the nominal temperature showed the best fatigue lives, and those cast at $28^{\circ}$ below showed the worse lives. One specimen cast at $28^{\circ}$ above the nominal casting temperature showed a lower fatigue life than IN-713C, whereas only one specimen cast at $28^{\circ}$ below NT ${ }^{\circ} \mathrm{C}$ showed a better life than expected for IN-713C.

In Fig. 2 only the data for IN-713C and IC-221M specimens cast $28^{\circ}$ above the nominal casting temperature are plotted in order to more clearly show the difference between the two 
materials. IC-221M has at least a factor of five (5) better fatigue life for equivalent stresses. The amount of scatter in the If $221 \mathrm{M}$ data is also reduced, neglecting the one very low datum. These data were generated on material from pours with similar compositions. The majority of data for specimens poured at $\mathrm{NT}^{\circ} \mathrm{C}$ (cf. Fig.1) were generated on castings from different heats ant these heats showed notable differences in composition.

Examination of fracture surfaces showed that crack initiation in the specimens occurred exclusively at internal defects, not at specimen surfaces. In each case, a gold-tinted, circular region was observed on the fracture surfaces, that, on the macroscopic level was crystallographic in nature and practically featureless on a microscopic scale. This is typical of stage I cracking [5] and involves the deepening of the initial crack on planes of high shear stress or persistent slip bands. An example of this stage I cracking is shown in Fig. 3. The final diameter of this region was determined by the proximity of the initiation site to the specimen surface. Once the internal flaw had grown to intersect the surface, crack propagation switched from stage I to stage II crack growth. Tensile overload, or stage III crack growth, occurred after notable stage II crack growth.

The fact that initiation did not occur at specimen surfaces combined with visual observations of the initiatıen sites indicated that casting porosity was responsible for initiation. This was confirmed by examining the fracture surfaces using a scanning electron microscope (SEM). Initiation was always associated with shrinkage porosity.

IC-221M and its variants are multiphase alloys with $\gamma, \gamma^{\prime}, \beta$, and $\mathrm{Ni}_{5} \mathrm{Zr}_{3}$ phases. A concern had existed that initiation might be occurring at the $\mathrm{Ni}_{5} \mathrm{Zr}_{3}$ phase, and while higher than normal levels of zirconium were observed on the surfaces of microporosity, no instances of initiation were observed at such second phase particles. Instead of having a deleterious effect on fatigue lives, the limited amount of data available seem to indicate that those alloys with higher $\mathrm{Zr}$ contents showed longer lives. Furthermore, while gas porosity was observed in polished metallographic specimens, no 
instances of initiation were attributed to gas or macroporosity.

From optical and SEM examination of fracture surfaces, a qualitative correlation can be deduced between size of porosity and life. To no one's surprise, larger pores were associated with shorter lives. The importance of the inherent porosity in limiting the observed fatigue strength of these alloys became even more obvious during testing of specimens with as-cast finishes. Failure frequently initiated at subsurface porosity, even though the specimen surfaces possessed a rough sandblasted finish. Sandblasting may have left beneficial residual compressive stresses on the surfaces.

\section{Discussion}

In wrought materials under axjal loading, fatigue failure nearly always begins at the surface [6]. The free surface and lack of constraint make initiation easier at the surface. When crack initiation occurs at internal casting defects such as porosity, potential exists for improving the high cycle fatigue strength if these defects can be eliminated. Since initiation occurred almost exclusively at casting porosity, it is important to understand the origins of porosity in these alloys.

Solidification microporosity in IC-396M has been studied by Sekhar et al. [7-9]. These results should apply to IC-221M since the alloys are very similar [8]. Porosity from the soiidification process can be divided into three categories, including; fluid flow macroporosity, gas porosity, and shrinkage microporosity. The shrinkage microporosity is thought to arise in solidification sequence after solidification of the primary $\gamma^{\prime}$. Microporosity has been observed at locations where the $\gamma^{\prime}$ from adjacent primary dendrites impinge [9]. This often results in porosity with a crack-like morphology, a condition which is extremely detrimental to fatigue resistance. In contrast, gas porosity is typically spherical in nature [9]. Crack-like defects require less applied stress to initiate a flaw in comparison to the spherical gas pores because this morphology magnifies the local stress more. Conversely, the 
initiating defect can be smaller for the same applied stress level. Macroporosity, which because of its sheer size is often fatal, was not encountered in the castings used in this study. However, it may be a factor in larger castings.

The effect of casting temperature in alloy IC-221M can also be inferred from the work of Sekhar et al. [7-9] on IC-396M. The pertinent results of their studies are summarized here and discussed in regards to the effect on fatigue life. First, both the average radius and volume fraction of gas porosity were relatively uilaffected by the cooling rate (ie., casting temperature). However, on all the fatigue fracture surfaces examined, no instances of initiation at gas pores were observed. Hence, no increase in fatigue life would be expected by reducing the amount of gas porosity.

Second, both the average radius and he volume fraction of macroporosity were notably reduced at faster cooling rates. Again, crack initiation was not observed at this type of defect and macroporosity is not of concern. Until the detrimental effects of microporosity can be mitigated, controlling gas porosity and macroporosity will not improve the fatigue properties notably.

The most important findings of Sekhar and co-workers concern shrinkage microporosity. They found that the average radius of microporosity was reduced be a factor of approximately four (4) as the cooling rate was increased from $0.04 \mathrm{Kelvin} / \mathrm{s}$ to $11 \mathrm{Kelvin} / \mathrm{s}$. At the same time, the volume fraction of microporosity was reduced by a factor of approximately two (2). Both of these observations are very important in understanding the improved fatigue lives noted for castings poured at the higher temperatures. Unfortunately, Sekhar and co-workers did not publish any data on the nature of the distribution of sizes of the microporosity. In the fatigue process, life is limited by the presence of a critically sized flaw in the highly stressed volume. The size of this critical defect is determined by its shape and the magnitude of the applied stress.

In the laboratory specimens tested under uniaxial fatigue loading, the largest shrinkage micropore present is generally the critical flaw, not one of average size. Hence, data on average pore 
dimensions does not provide anything other than qualitative information. Even so, when the reduction in average pore size is considered in combination with the reduction in the volume fraction of microporosity, one can assume that the distribution of pore sizes has been shifted to smaller sizes. If this is true and the shape of the distribution remains the same, the probability of larger pores is reduced and longer lives would be expected. Comparison of the fatigue data for specimens cast at $28^{\circ}$ above and below the nominal pouring temperature show a factor of ten difference in average fatigue life.

IC-221M was observed to have longer lives than the IC-396M alloy. This can be explained in terms of the volume percent, size, shape, and distribution of solidification microporosity in these alloys. Trends observed between the size, shape, and distributions of porosity and cooling rate are very similar [8], but IC-221M shows reduced amounts of microporosity and smaller average dimensions for each pore. (Refer to Fig. 4) Both the reduction in volume fraction of microporosity and average size should increase the number of cycles required to initiate a crack.

Sekhar and co-workers also found that the mean grain radius increased by a factor of approximately 20 when the cooling rates were decreased from $0.5 \mathrm{~K} / \mathrm{s}$ to $11 \mathrm{~K} / \mathrm{s}$. In the absence of appreciable creep or environmental attack, a refined grain size should result in improved high cycle ratigue resistance [10]. Grain size has its greatest effect on fatigue life in the low-stress, high cycle fatigue regime in materials in which stage I cracking occurs [11]. This is thought to be one of the factors contributing to the increased fatigue lives observed in the castings poured at the highest temperature $\left(\mathrm{NT}+28^{\circ} \mathrm{C}\right)$. However, reductions in the volume fraction and average dimensions of the crack-like microporosity are believed to be the main factor contributing to a better fatigue strength in this material.

Scatter in fatigue lives is a function of two factors, including the size of the critical casting defect, and second, the location of this flaw. Though not easily quantified, the location of the 
initiation site does appear to have a considerable influence on the observed fatigue lives. The amount of stage I crack growth is controlled by the location of the initiation site relative to the specimen surface. Furthermore, the rate of crack propagation in stage I is generally very low, on the order of angstroms per cycle, compared with crack propagation rates of microns per cycle in stage II [5]. Life in these cast nickel aluminide specimens is the sum of the cycles spent in each stage of the failure process; initiation, stage I crack growth, and stage II crack growth. Hence, those specimens where initiation occurs closer to the center of the specimen will have a greater amount of stage I crack growth and would be expected to have notably longer lives.

\section{Conclusions}

The results of the high cycle fatigue tests on as-cast IC-221M show that this alloy has better fatigue strength than as-cast $\mathrm{IN}-713 \mathrm{C}$ at $650^{\circ} \mathrm{C}$. Cyclic lives of $10^{7}$ cycles were observed in IC-221M at stresses of $517 \mathrm{MPa}$. This represents a considerable improvement over the $10^{7}$ cycle fatigue strength of IN-713C, estimated at $450 \mathrm{MPa}$.

The uniaxial fatigue performance of cast IC-221M Ni$i_{3} \mathrm{Al}$ alloys is a function of the cooling rate of the casting from the melt, with higher cooling rates promoting better high cycle fatigue resistance. Initiation in these alloys was almost exclusively at solidification microporosity. The size, shape, distribution and volume of this microporosity is strongly influenced by cooling rates. A reduction in the volume fraction of microporosity and smaller pores are associated with faster cooling rates and this is responsible for the improved fatigue lives of IC-221M at higher casting temperatures. In a similar fashion, the better performance of IC-221M in comparison to IC-396M is attributed to a reduction in the amount and average size of the microporosity in the castings of IC-221M. 


\section{Acknowledgements}

This work was sponsored in part by the U.S Department of Energy, Assistant Secretary for

Conservation and Renewable Energy, Office of Industrial Technologies, Advanced Industrial Concepts Division, Advanced Industrial Materials Program under contract DE-AC05-84OR21400 with Martin Marietta Energy Systems, Inc. Many helpful discussions were held with R.W. Swindeman. The manuscript was reviewed by G.R. Romanowski and R.W. Swindeman, and was prepared by S.D. Samples.

\section{References}

1. K Aoki and O Izumi, Nippon Kinzoku Gakkaishi 43, 1190 (1979).

2. C.T. Liu, C.L. White, and J.A. Horton, Acta Metall. 33, 213 (1985).

3. C.T. Liu, V.K. Sikka, J.A. Horton, and E.H. Lee, Alloy Development and Mechanical Properties of Nickel Aluminide ( $N i_{3} A l$ ) Alloys, ORNL-6483, Oak Ridge National Laboratory, Oak Ridge, TN (1989).

4. V.K. Sikka, Commercialization of Nickel Aluminides, in High Temperature Aluminides and Intermetallics, S.H. Whang, eds., The Minerals, Metals \& Materials Soc., 1990, 505-520.

5. W.J. Plumbridge and D.A. Ryder, Metall. Rev., 14, no. 136, 1969.

6. G.E. Dieter, Mechanical Metallurgy, $2^{\text {nd }}$ Ed., McGraw-Hill Book Co., 1976, p. 427.

7. C.J. Cheng and J.A. Sekhar, Solidification Microporosity in Equiaxed Multi-Component Nickel Aluminide, Mat. Res. Symp. Proc., Vol. 213, 1991, Materials Research Society.

8. C.J. Cheng and J.A. Sekhar, publication in preparation.

9. C.T. Ho, C.J. Cheng, and J.A. Sekhar, Solidification Microporosity in Directionally Solidified 
Multicomponent Nickel Aluminide, Met. Trans., Vol. 22A, 1991, 225-234.

10. A.W. Thompson and W.A. Backofen, Acta Metall., 19, 1971, 597-606.

11. M.R. Hempel, in Fracture, The Technology Press and John Wiley and Sons, New York, 1959, 376.

\section{DISCLAIMER}

This report was prepared as an account of work sponsored by an agency of the United States Government. Neither the United States Government nor any agency thereof, nor any of their employees, makes any warranty, express or implied, or assumes any legal liability or responsibility for the accuracy, completeness, or usefulness of any information, apparatus, product, or process disclosed, or represents that its use would not infringe privately owned rights. Reference herein to any specific commercial product, process, or service by trade name, trademark, manufacturer, or otherwise does noi necessarily constitute or imply its endorsement, recommendation, or favoring by the United States Government or any agency thereof. The views and opinions of authors expressed herein do not necessarily state or reflect those of the United States Government or any agency thereof. 
TABLE 1. Chemical Analysis of Cast $\mathrm{Ni}_{3} \mathrm{Al}$ Alloys Based on IC-221M Composition.

\begin{tabular}{ccccccc}
\hline & \multicolumn{7}{c}{ Weight Percent } \\
\cline { 2 - 7 } Element & IC-221 & $\begin{array}{c}\text { IC-221M } \\
(\text { Bt.19-2) }\end{array}$ & $\begin{array}{c}\text { IC-221M } \\
(\text { Bt.19-3) }\end{array}$ & $\begin{array}{c}\text { IC-221M } \\
(\text { Ht.13893) }\end{array}$ & $\begin{array}{c}\text { IC-221M-1 } \\
(\text { Ht.13894) }\end{array}$ & $\begin{array}{c}\text { IC-221M-2 } \\
(\text { Ht.13895) }\end{array}$ \\
\hline $\mathrm{Cr}$ & 7.8 & 7.48 & 7.74 & 7.74 & 7.76 & 7.76 \\
$\mathrm{Ni}$ & 82.18 & 81.8 & 81.6 & 81.15 & 81.25 & 81.25 \\
$\mathrm{Mo}$ & -- & 1.44 & 1.43 & 1.43 & 1.61 & 1.61 \\
$\mathrm{~B}$ & 0.020 & 0.012 & 0.012 & 0.008 & 0.008 & 0.008 \\
$\mathrm{Zr}$ & 1.70 & 1.82 & 1.89 & 1.70 & 1.28 & 1.28 \\
$\mathrm{Al}$ & 8.5 & 7.39 & 7.29 & 7.98 & 8.10 & 8.10 \\
\hline
\end{tabular}

TABLE 2. Tensile Properties of Cast IC-221M based Alloys at $650^{\circ} \mathrm{C}$.

\begin{tabular}{cccccc}
\hline Alloy & Ht. \# & $\begin{array}{c}0.2 \% \text { Yield } \\
\text { Strength } \\
(\mathrm{MPa})\end{array}$ & $\begin{array}{c}\text { Tensile } \\
\text { Strength } \\
(\mathrm{MPa})\end{array}$ & $\begin{array}{c}\text { Total } \\
\text { Elongation } \\
(\%)\end{array}$ & $\begin{array}{c}\text { Reduction } \\
\text { of Area } \\
(\%)\end{array}$ \\
\hline IC-221M & 13893 & 693.8 & 940.5 & 21.74 & 19.76 \\
IC-221M-1 & 13894 & 702.5 & 871.2 & 13.79 & 10.83 \\
IC-221M-2 & 13895 & 697.4 & 904.2 & 17.42 & 15.07 \\
IC-221M & $19-02$ & 673.4 & 915.2 & 20.4 & 18.1 \\
IC-221M & $19-03$ & 681.8 & 899.7 & 13.0 & 11.3 \\
\hline
\end{tabular}

In all tests, a strain rate of $2.67 \times 10^{-3} / \mathrm{s}$ was used. 
ORNL DWG 91-14585

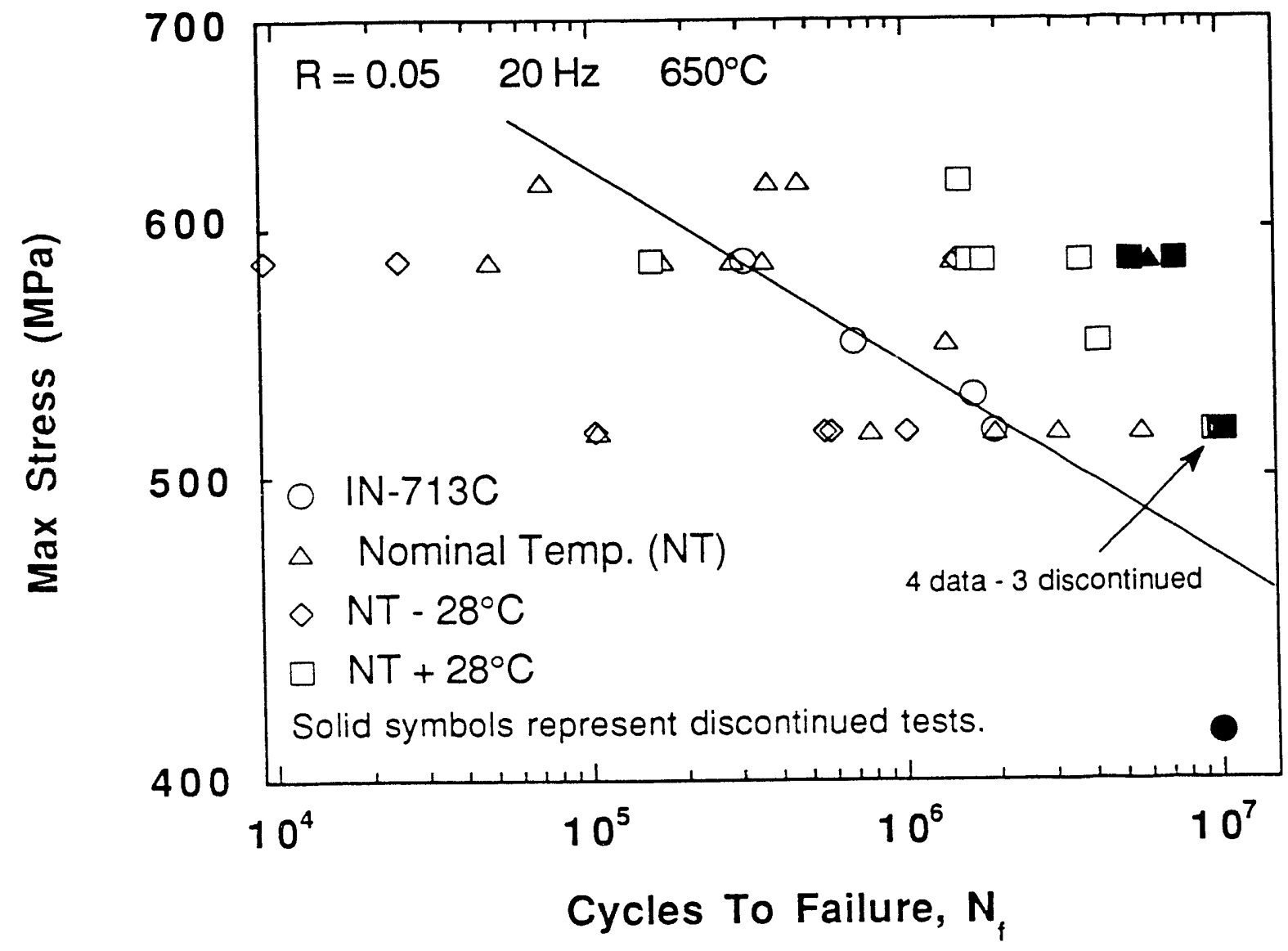

Fig. 1. Results of fatigue tests at $650^{\circ} \mathrm{C}$ on nickel aluminides. Results are shovin for casting poured at the nominal casting temperature and at temperatures $28^{\circ} \mathrm{C}$ above and below this temperature. 


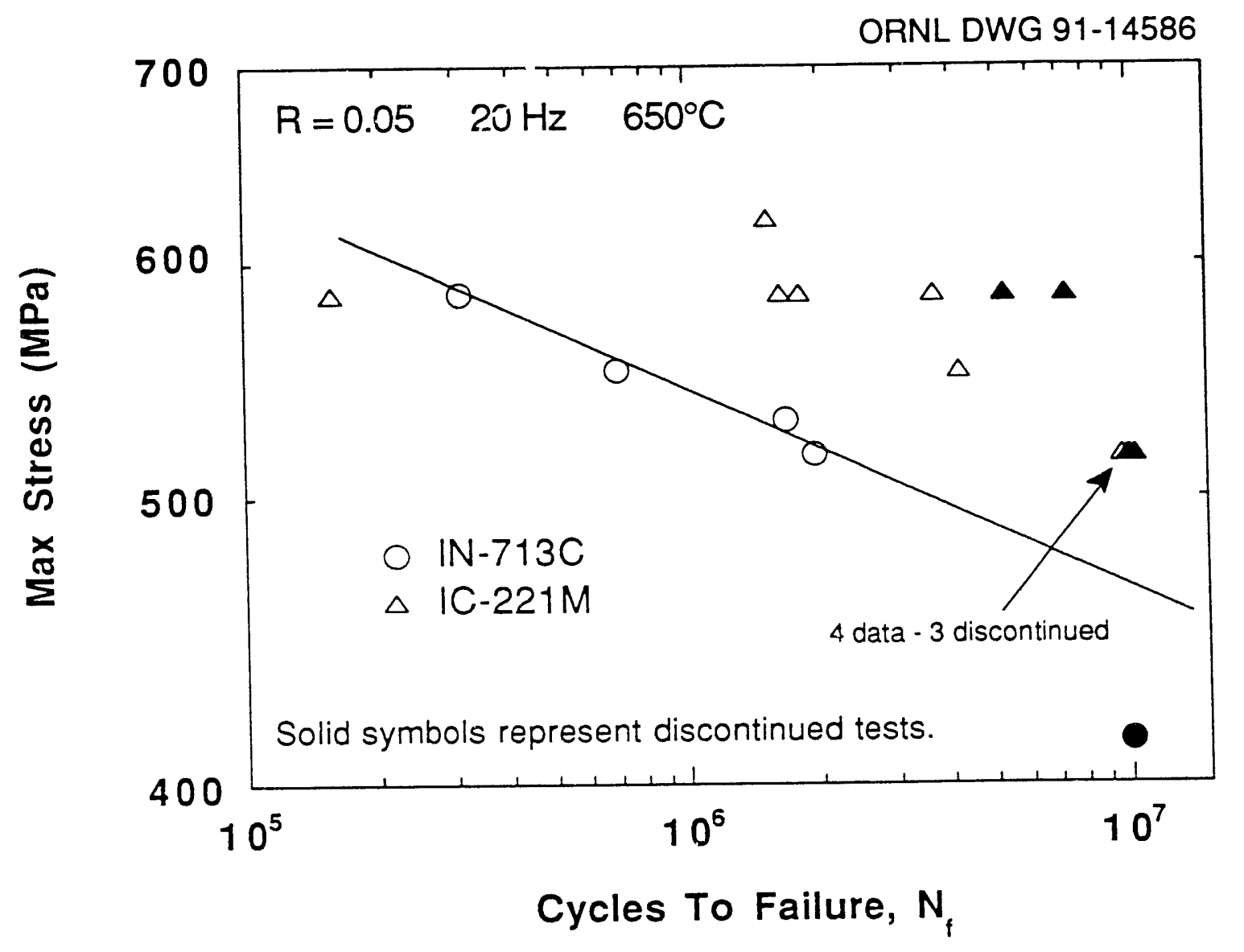

Fig. 2. A comparison of axial fatigue tests at $650^{\circ} \mathrm{C}$ on IC- $221 \mathrm{M}$ cast at $28^{\circ} \mathrm{C}$ above the nominal pouring temperature to those obtained for as-cast $\mathrm{IN}-713 \mathrm{C}$. 


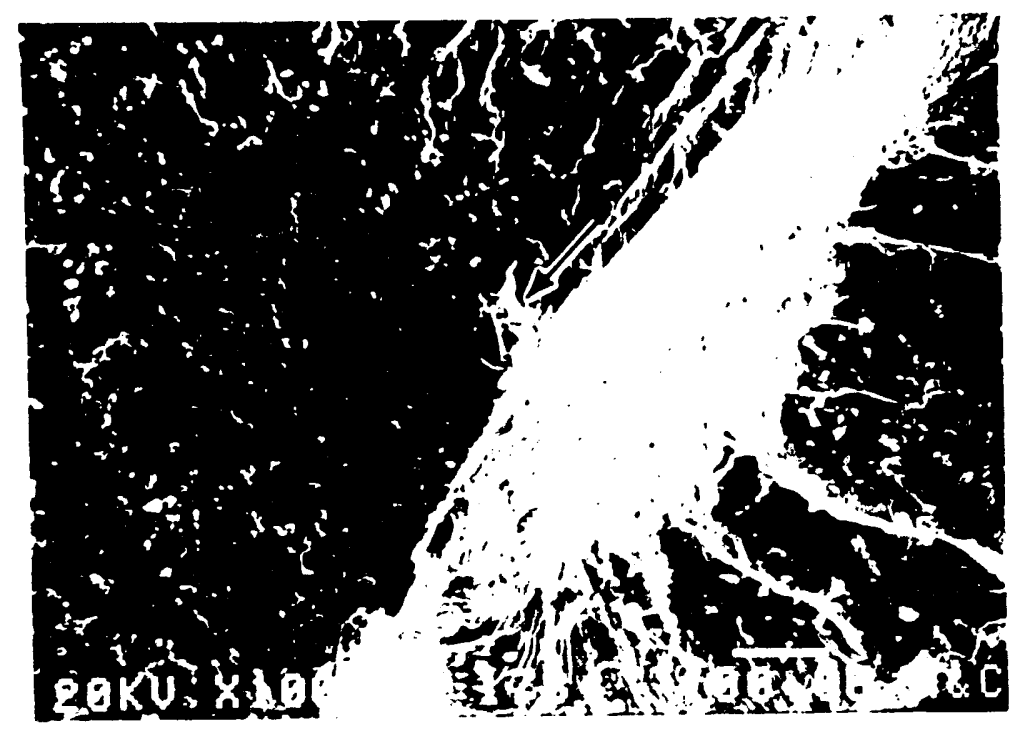

ORNL-PHOTO-9316-91

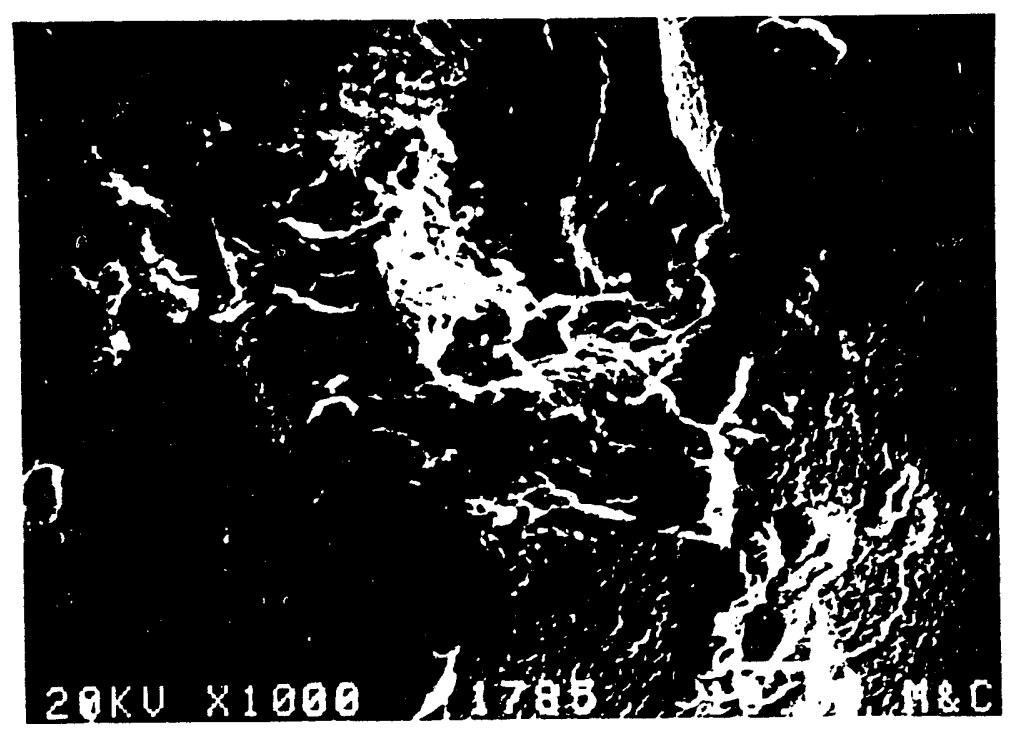

(b)

Fig. 3. A typical example of crack initiation at microporosity in cast $\mathrm{Ni}_{3} \mathrm{Al}$ alloys based on the IC-221.M composition. (a) Note the faceted nature of the fracture surface in region, typical of stage I crack growth. Initiation occurred at shrinkage microporosity (indicated hy arrow). (b) Higher magnification photograph showing the initiation site in more detail. 


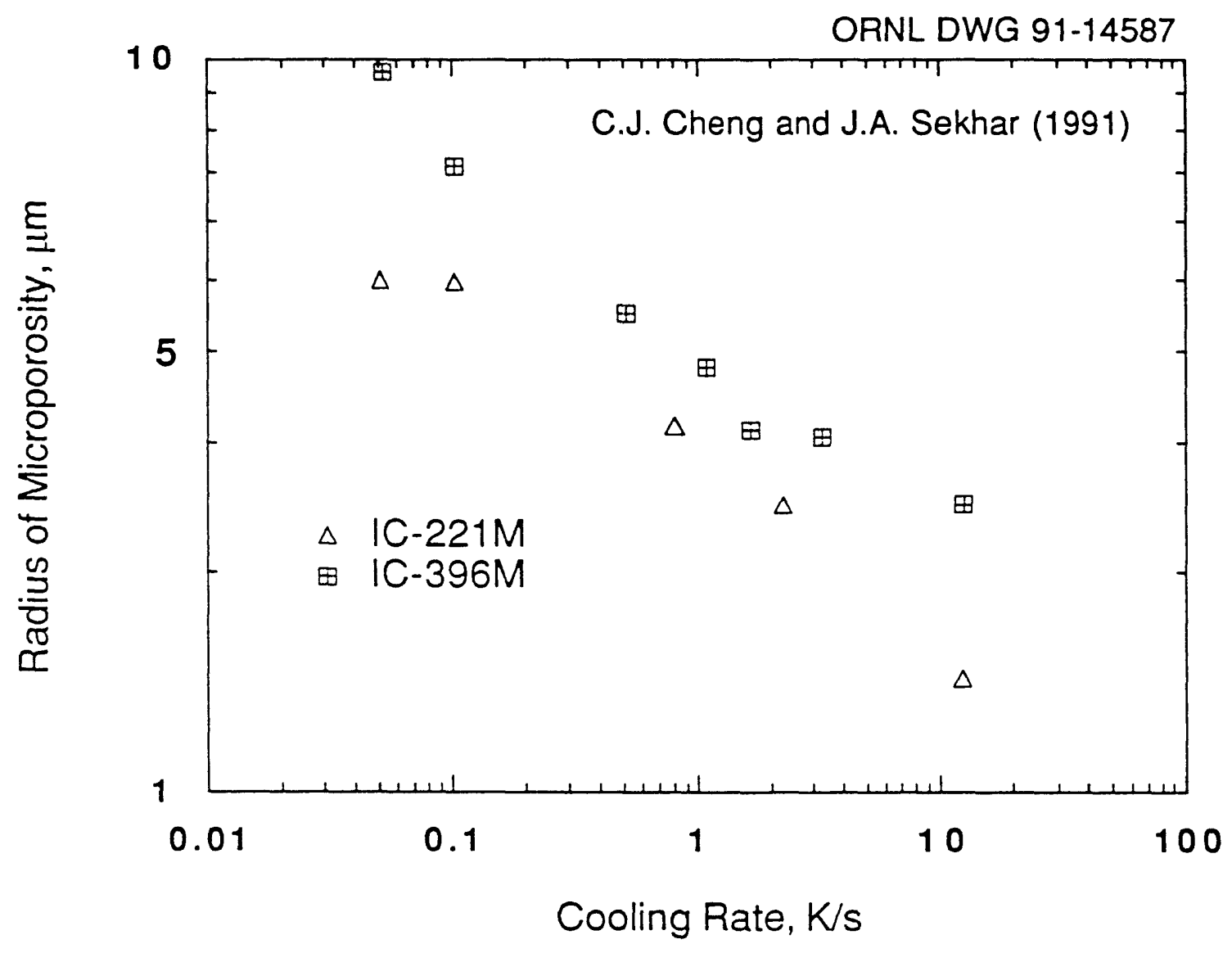

Figure 4. Comparison of average radius of microporosity defects as a function of solidification cooling rate in alloys IC-396M and IC-221M [8]. IC-221M has a smaller average defect size at all cooling rates. 

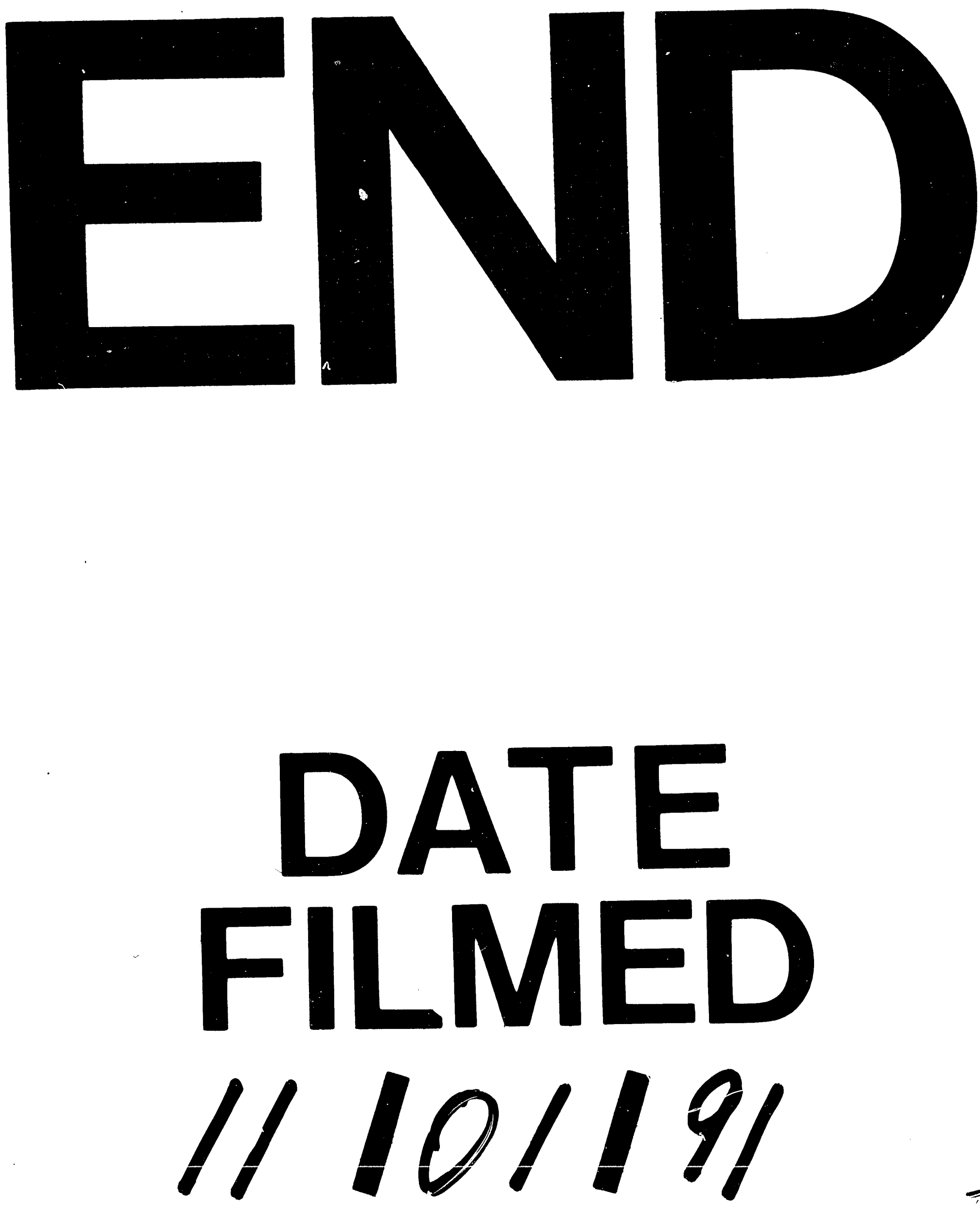

$\bar{I}$ 
